El espacio editorial argentino y la construcción de los ferrocarriles metropolitanos como problema público

Candela Hernández y Ezequiel Saferstein

Question, Vol. 1, N.ำ 57, e017, enero-marzo 2018. ISSN 1669-6581

http://perio.unlp.edu.ar/ojs/index.php/question/article/view/4330

FPyCS | Universidad Nacional de La Plata

La Plata | Buenos Aires | Argentina

Recibido: 28-08-2017 Aceptado: 20-10-2017

Cita sugerida: Hernández, C., y Saferstein, E. (2018). El espacio editorial argentino y la construcción de los ferrocarriles metropolitanos como problema público. Question, 1(57), e017. doi :https://doi.org/10.24215/16696581e017

\title{
El espacio editorial argentino y la construcción de los ferrocarriles metropolitanos como problema público
}

The Argentinian publishing market and the construction of the metropolitan railways as a public problem

\section{Candela Hernández}

Instituto de Investigaciones Gino Germani; Facultad de Ciencias Sociales; Universidad de Buenos Aires/ Consejo Nacional de Investigaciones Científicas y Técnicas (Argentina) candeher@gmail.com

\section{Ezequiel Saferstein}

Centro de Documentación e Investigación de la Cultura de Izquierdas en Argentina; Universidad Nacional de San Martín/ Universidad de Buenos Aires/ Consejo Nacional de Investigaciones Científicas y Técnicas (Argentina) esaferstein@gmail.com 


\section{Resumen}

El objetivo del artículo es abordar el rol que tuvo el sector editorial, los editores y los autores de libros de coyuntura en el tratamiento de los ferrocarriles de la Región Metropolitana de Buenos Aires (RMBA) como problema público. Se realiza una conceptualización teórica acerca de los problemas públicos y del rol del sistema de medios de comunicación y del sector editorial en la producción y reproducción de dichos problemas. Se da cuenta del estado de situación de la industria editorial para el período de análisis, haciendo énfasis en el comportamiento de los libros de no ficción que abordan la coyuntura política, específicamente los que trataron a la corrupción como tema central. Por último, se aborda el análisis de los libros especializados en la cuestión ferroviaria, ahondando en el estudio de dos casos representativos. A partir de una serie de datos de carácter cuantitativo (registro de libros de política publicados entre 2003 y 2015) y cualitativo (entrevistas, observaciones), se aborda el interrogante acerca de cómo opera el "efecto libro" en la configuración de un problema público y de especialistas o referentes en torno a este problema.

Palabras clave: problemas públicos; mediación editorial; editores; best sellers.

\section{Abstract}

The aim of this paper is to analyze the role played by the publishing field, the editors and the authors of instant-books books in the treatment of the Metropolitan Region of Buenos Aires (RMBA) railways system as a public problem. In first place, the paper exposes a theoretical conceptualization about the public problems and the role of the media system and the publishing market in the production and reproduction of those type of problems. In second place, the work analyzes the status of the publishing industry nowadays, focusing on the behavior of non-fiction political books, specifically those that treated corruption as a central issue. Finally, we analyze two books about the railway system situation. Based on a series of quantitative data (register of policy books published between 2003 and 2015) and qualitative data (interviews, observations), the paper focuses on the question about how the book system written by specialists or referents operates in the configuration of a public problem.

Keywords: public problems; editorial mediation; editors; best sellers.

En la Argentina, entre 2002 y 2015, el sistema ferroviario de pasajeros de la Región Metropolitana de Buenos Aires (RMBA) fue progresivamente ocupando espacios como tema de 
preocupación social en la escena pública. Una diversidad de actores participó de este proceso, al jerarquizar la emergencia de la temática en arenas tales como el sistema judicial y político y distintos ámbitos de la cultura, como la academia, los medios de comunicación y el mercado editorial. El surgimiento de los ferrocarriles como objeto de atención pública estuvo vinculado a la degradación creciente que la calidad del servicio presentó en esos años. Las condiciones negativas a las que fueron expuestos sus pasajeros resultaron un verdadero padecimiento. En este escenario emergieron conflictos que expresaron directa e indirectamente la disconformidad con el servicio prestado, dimensión que operó efectivamente sobre su visibilización y tratamiento público.

El movimiento generado en torno al caso estuvo motorizado por actores particulares que se conformaron como referentes o portavoces de la temática. Periodistas, editores, víctimas y familiares, políticos, jueces y fiscales protagonizaron los debates en torno al tema. Analizado desde el tratamiento brindado por la prensa escrita, distintas controversias comenzaron a traslucir y consolidar la idea acerca de la existencia de un entramado de corrupción como elemento explicativo de la degradada calidad del servicio. La construcción del sistema ferroviario como problema público, así reflejado en este espacio de producción de la opinión pública, se consolidó bajo el axioma "la corrupción mata" luego de que se produjera el accidente más trágico de la historia de los ferrocarriles metropolitanos de la Argentina en 2012 (1) (Hernández, 2017). El caso analizado contribuyó a caracterizar a un tipo específico de la práctica de la corrupción en el contexto local, que expresa una radicalización de las potenciales consecuencias que esta pudiera tener, en el sentido de que la corrupción resultó ser más que una mera apropiación económica de fondos del Estado por parte de sus funcionarios ya que, en su resultante mediata, llegó a tener la capacidad de "matar".

El eje de la discusión anclado a esta práctica excedió al problema ferroviario al inscribirse en un clima político más amplio. Ya desde los años noventa en la Argentina se había instalado una visión dominante en torno a la idea de que la corrupción se constituía como un elemento transversal y característico de su sistema político (Pereyra, 2013). Esta imagen se tradujo en un tratamiento diferencial tanto en términos cuantitativos como cualitativos del seguimiento dado por la prensa a los casos de corrupción. El aumento de su cobertura estuvo ligado a una mayor especialización de periodistas dedicados a seguir la problemática, conformándose como verdaderos expertos. Esta cualidad les permitió trascender el ámbito de los medios de comunicación masivos bajo el formato de producción de la noticia, trazando relaciones con otros espacios de producción cultural que, bajo sus lógicas propias, también se vieron interpelados por la temática.

Uno de estos espacios es el sector editorial. Articulándose con el sistema de medios, las grandes editoriales posicionaron sus colecciones de libros de no ficción, escritos por periodistas especializados, quienes al conformarse como autores de libros, fortalecieron su 
lugar de referentes de opinión. Grandes medios como La Nación, Clarín y Página/12, y editoriales transnacionales como Penguin Random House (PRH) y Planeta, concentraron un poder de difusión y visibilidad sumamente potente. La presencia de la temática de la corrupción en los medios masivos, en las librerías, así como en las redes sociales y otros ámbitos dan cuenta de un amplio sistema de comunicación que opera como usina de temas y debates de interés público.

El objetivo de este artículo es abordar, a partir del estudio de caso, el rol que tuvo el sector editorial, los editores y los autores de libros de coyuntura en el tratamiento de los ferrocarriles de la RMBA como problema público. Esta indagación habilita a formular interrogantes más generales que apuntan a problematizar en torno a las relaciones entre el sector editorial, los medios de comunicación, la agenda mediática, la esfera pública y la política: ¿Qué nos puede aportar el análisis de los modos de producción editorial en cuanto a cómo se construye un problema público? ¿Cómo trabajan en la actualidad los editores para la publicación de libros de coyuntura? ¿En qué medida los autores (periodistas, en su mayoría) se posicionan como actores legítimos en la construcción de un problema? ¿Cómo opera el "efecto libro" en la configuración de un problema público y de especialistas o referentes en torno a este problema? El trabajo aquí presentado recupera una serie de datos de carácter cuantitativo y cualitativo. Entre ellos se destaca una base de datos construida a partir del registro ISBN de libros sobre la coyuntura política publicados entre 2003 y 2015 por las grandes, medianas y pequeñas editoriales (2). Como complemento, se recurrió al análisis de una serie de entrevistas en profundidad realizadas a editores y otros agentes de las empresas editoriales, así como a periodistas/autores de libros de coyuntura. Además, se trabajó con registros de prensa para contextualizar la emergencia pública de los libros publicados e identificar las campañas de difusión de los mismos.

\section{Los problemas públicos, el rol del periodismo y el sector editorial}

La construcción de un problema social de carácter público, consiste en un proceso colectivo por el cual ciertas condiciones son percibidas y definidas por un conjunto de actores como nocivas para una porción considerable de la población, aunque no todas se transforman necesariamente en epicentro de conflicto o controversia en el ámbito público (Loseke, 2011; Gusfield, 2014). Para que esto suceda, determinadas circunstancias deben convertirse en asunto de reflexión y objeto de la protesta al tiempo que, a través de su publicitación, en recurso y propósito para la acción pública.

En este movimiento existen distintas arenas -medios de comunicación e industrias culturales, órganos de representación política, comunidad científica, entre otras (Hilgartner y Bosk, 1988) 
desde las que se publicitan determinadas problemáticas sociales. Al convertirse en objetos de atención y discusión en el espacio público, las representaciones circulantes en torno a ellas se presentan como heterogéneas $\mathrm{y}$, en ocasiones, incoherentes respecto de las atribuciones dadas en los circuitos por los que transitan en su proceso de problematización. En la medida en que un tema atraviesa los distintos ámbitos y éstos, a su vez, logran articularse en función de caracterizarlo y problematizarlo, contribuyen a amplificar su atención pública. En este sentido, hay una diversidad de actores socialmente significativos que protagonizan las disputas en torno a la problematización de un determinado tema, de acuerdo a sus recursos materiales y simbólicos disponibles.

Los medios de comunicación y el sector editorial se conforman como escenarios privilegiados de producción y difusión de las controversias y disputas que giran en torno a ciertos temas, con una capacidad de llegada a una variedad y multiplicidad de públicos. Ambos son espacios importantes para pensar la construcción y difusión de debates y problemas públicos. A través de ellos, se pueden objetivar ciertas temáticas y convertirlas en una preocupación social y colectiva, con capacidad de influir sobre el ejercicio gubernamental y la política en general (Sorá, 2008).

Rescatados en su singularidad, los medios de comunicación tienen una lógica de funcionamiento que propicia la interacción entre distintos ámbitos. Su tipo de producción coyuntural y diaria se ejercita en la administración de sucesos relativamente previsibles o inesperados que redundan rápidamente en productos circulables (Tuchman, 1997). El resultado de la actividad periodística es la noticia, desde la que se producen y reproducen criterios de selección e intelección de la realidad social. La tarea periodística plasmada en el carácter que este objeto asume, trabaja en la producción de representaciones que encuentran una rápida y amplia circulación social (Valcarce, 2005).

En este terreno, los periodistas políticos son actores complejos al operar en los distintos niveles que hacen al proceso de construcción colectiva de un determinado problema, por el carácter que tiene su participación en la escena mediática. Dado su reconocimiento frente al público, frente a sus pares y también según la posición que ocupa la empresa en la que participan dentro del campo de los medios, están legitimados como voz autorizada para participar de la disputa simbólica que supone el proceso atributivo de una determinada situación problemática. Desde una posición privilegiada, pueden aportar a la construcción de acontecimientos que serán considerados como "políticos", con lo cual puede decirse que tiene un relativo poder de influencia sobre esta dimensión (Vommaro y Baldoni, 2012). En otro movimiento se distancian en el ejercicio de decodificar las prácticas políticas en una clave moralizadora de dichas acciones, fundada en un "saber hacer" profesionalizado de la actividad periodística que goza de neutralidad en relación con las tomas de decisiones políticas (Pereyra, 2013). Este tipo de periodistas también cumple la función de articuladores de ámbitos de discusión, evidenciados 
en el tranzado de relaciones entre el sector mediático y editorial al que frecuentemente ingresan como autores de libros que abordan temas de coyuntura.

El sector editorial históricamente se constituyó como una industria cultural de carácter discontinuo, con tiempos de producción más prolongados. Al estar integrado por actores posicionados en espacios de intervención socialmente más prestigiados que los que ocupan los actores de los medios de comunicación (como el campo intelectual, la academia y el ámbito literario), los bienes que produce el sector editorial tienen efectos que pueden operar de manera diferente en términos cualitativos respecto a la prensa escrita. Esto se da por una serie de razones explicitadas por Robert Darnton (1993). El producto libro, en contraposición a la noticia, tiene la capacidad de conservarse y perdurar en el tiempo. Logra propagar mensajes de una manera articulada bajo la idea de una totalidad y de "obra" generalmente accesible para un grupo más restringido que la amplia "opinión pública". Estos factores le brindan a la editorial, al autor, a su escrito y al objeto materializado en forma de libro una legitimidad social mayor que la que poseen otros espacios simbólicos más atravesados por el mercado masivo.

En este contexto, el editor es un actor clave en la difusión de temas que pueden ser amplificados, al seleccionar textos, impulsar temáticas y autores y ponerlos a circular por ámbitos culturales y políticos. Como afirma Bourdieu, "tiene el poder totalmente extraordinario de asegurar la publicación, de hacer acceder un texto y un autor a la existencia pública, conocido y reconocido" (2009). En su relación con el sistema de medios, puede hacer que un periodista de un diario adquiera renombre en tanto autor de libros. Esto no implica un simple complemento del rol de la prensa escrita, sino una operación de legitimación cultural y socialmente amparada en una obra y en una creencia colectiva asociada al mundo del libro (Sorá, 2008).

En los últimos años, la industria editorial entró en un proceso de transformaciones que la acercaron en varios sentidos a la lógica de funcionamiento de los medios y del periodismo. En los años noventa los grandes grupos editoriales desembarcaron en el país absorbiendo las editoriales locales en un proceso de expansión hacia toda Latinoamérica. Desde ese entonces, grupos de capital transnacional, como PRH y Planeta, lideran el mercado de producción, circulación y venta de libros. Producto de estas transformaciones, la actividad editorial pasó a estar más concentrada. Dicho pasaje llevó a que se aplicaran nuevas estrategias de producción y comercialización, conformaron empresas que debían rendir cuentas a las casas matrices y segmentaron las etapas de la producción, en línea con otras industrias culturales como la de la prensa, el cine y la discográfica (Thompson, 2012). Así, las editoriales se adaptaron a la lógica empresarial global siguiendo el modelo organizacional de los conglomerados que las adquirieron, especializando el personal dentro de cada una de las nuevas áreas e incorporando nuevos actores vinculados al mundo del marketing, la comunicación y las finanzas. 
El proceso de concentración convirtió a la edición en un espacio de valorización financiera cuyo propósito principal es invertir para recuperar beneficios en el corto plazo. Por ello la exigencia de rentabilidad propia de estas empresas convirtió la producción de bestsellers -libros de venta masiva y rápida- en un imperativo (Dujovne, 2016). El modelo de "fondo editorial" por medio del cual un director editorial se legitimaba, fue reemplazado por un sistema dominado por la producción de novedades que aspiran a venderse rápida y masivamente.

Gran parte de estas novedades tienen un ciclo de vida corto, que varía en función de su éxito. Son libros cuyas temáticas giran en torno a cuestiones que responden a acontecimientos vinculados a la lógica de la agenda de los grandes medios de comunicación y las corrientes de opinión masivas. Las editoriales apuestan a que sus novedades sean bestsellers, por lo que estos títulos se construyen como tales, mediante tiradas cortas. Si el título funciona, se reimprime.

Las exigencias de rentabilidad, la adecuación de los catálogos a la lógica de la novedad, la circulación y la obsolescencia rápida llevan a que el espacio editorial se asemeje en funcionamiento a la dinámica de los medios de comunicación, en el sentido de la producción para el corto plazo, fuertemente atravesada por la coyuntura.

\footnotetext{
Nosotros tenemos un funcionamiento que no es el típico de una editorial de libros. Es más un funcionamiento de revista. Pese a que hay algunos libros que los podemos cerrar con muchísima antelación, en los libros de investigación o denuncia lo que prima es la cuestión coyuntural (Director Editorial, Planeta, Comunicación personal, 14 de junio de 2016).
}

Esta nueva dinámica impacta sobre las prácticas de los editores, quienes construyeron una nueva forma de "entender el negocio" que la diferencia de otras modalidades anteriores (Miguel y Saferstein, 2016). Estos agentes adquieren habilidades que los asemejan al estilo de los productores de contenidos en los medios: proponen temáticas y autores y siguen de cerca el circuito de producción de un libro, participando también en su posterior comercialización y difusión. Lejos de esperar a los autores y a sus originales, los editores "salen a buscar" a los libros, proponiendo en los comités las temáticas que puedan ser atractivas para un público esperado.

Aun en el marco de una gran empresa global, los editores desarrollan prácticas que los ubican como actores claves en el campo editorial y en su labor específica establecen lazos con las esferas políticas, periodísticas intelectuales y culturales. El editor es el actor que encarna el proceso de mediaciones que dan como resultado la construcción y consagración de un autor, asociado a un contenido materializado en un libro que será puesto en circulación y apropiado por un grupo de lectores. Analizar las lógicas internas de producción del espacio editorial, las prácticas y representaciones de sus actores en torno a la publicación de libros periodísticos, puede ser una vía de entrada fructífera para analizar cómo determinados temas, en este caso, 
la calidad del servicio ferroviario de pasajeros, se constituyen en objeto de problematización social en la escena pública.

\section{Los bestsellers de coyuntura política durante la última década}

Caracterizados como un "boom editorial" por parte de la prensa y por sus propios editores y escritores, numerosos títulos considerados "bestsellers políticos" que tuvieron como eje la discusión sobre los gobiernos kirchneristas fueron publicados, difundidos y consumidos por amplios sectores entre 2003 y 2015 (Blanc, 2013). Entre esos años, alrededor de 250 editoriales locales publicaron 3.857 títulos coyunturales en relación con la política económica del gobierno, su política de derechos humanos, la figura presidencial, la militancia así como los casos de corrupción más resonantes. Además del crecimiento de estos géneros, la visibilidad mediática que obtuvieron debido a la vigencia coyuntural de sus temáticas y a la presencia de sus autores, potenció su difusión y circulación, amparada por la "ingeniería editorial" de los grandes grupos quienes sostienen y motorizan esta producción, gracias a sus sólidas estructuras para publicar.

El grupo PRH es la editorial que más títulos relacionados con la coyuntura política publicó en el período, seguido por Planeta. Los grandes grupos publicaron un cuarto de los títulos políticos registrados (1.173) en el período, lo que evidencia la hegemonía de estas editoriales. Como se observa en el siguiente gráfico con respecto a la evolución temporal de estos géneros, el período muestra un crecimiento relativamente sostenido, con leves caídas hasta 2012, año pico de este crecimiento, con casi 200 títulos de coyuntura política. La tendencia de producción de estos libros revela que entre 2011 y 2013 ocurre el pico más alto de su crecimiento, en sintonía con determinados acontecimientos políticos (elecciones presidenciales y de medio término) o ciclos económicos más generales (recuperación de la crisis económica mundial de 2008). 


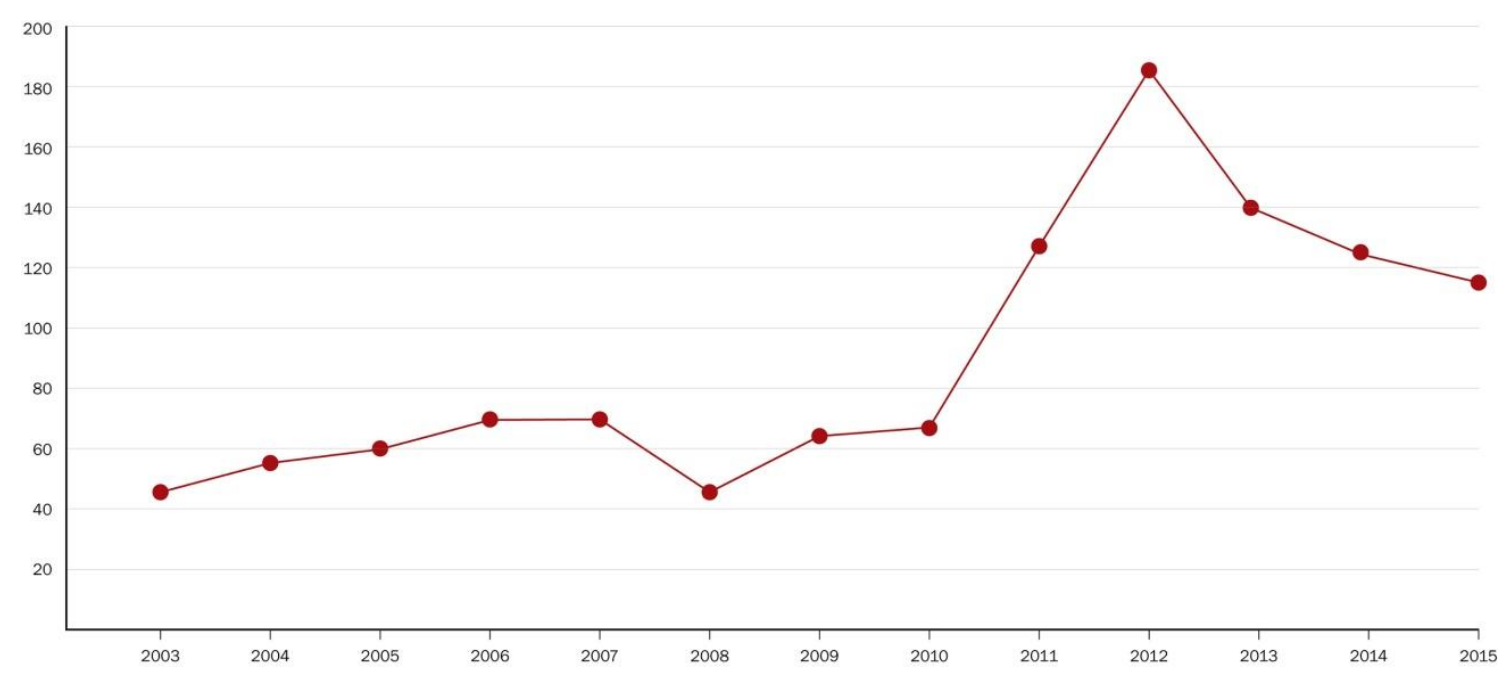

Gráfico1: Evolución de títulos políticos en los grandes grupos (2003-2015). Fuente: elaboración propia a partir de datos de la Agencia Argentina de ISBN (2016).

El crecimiento de la producción de títulos de libros políticos está acompañado por las altas ventas y por la conformación de series de autores que se constituyen en figuras de referencia para estos géneros (Blanc, 2013). Entre los autores que más títulos publicaron en el período, la lista la encabezan Marcos Aguinis, Santiago Kovadloff, Juan Bautista Yofre, Ceferino Reato y Luis Majul. Es destacable la importancia del grupo PRH y Planeta en la publicación de estos autores, lo que da cuenta de una política de autor como objetivo editorial: la construcción de autores "marca" como figuras de referencia en sus espacios de producción y su consagración en tanto especialistas en determinados temas con presencia en el debate público y mediático.

Entre este segmento de libros, los títulos que específicamente abordan la temática de la corrupción política ocupan una gran importancia. En sintonía con el auge mediático de casos resonantes de corrupción desde los años noventa, el mercado editorial fue uno de los espacios de relevancia en donde su caracterización fue disputada. Especialmente, periodistas de investigación y editores del Grupo Planeta que dirigían la colección Espejo de la Argentina instalaron, potenciaron y le dieron entidad a la corrupción como "problema público", al editar las investigaciones de quienes se convirtieron en referentes del periodismo en los medios masivos. El trabajo de los periodistas de investigación (motorizados por los medios y las grandes editoriales), así como de expertos en corrupción, jueces y fuerzas políticas, hicieron de la transparencia un "estandarte" de la lucha contra la corrupción (Pereyra, 2013; Vommaro y Baldoni, 2012). En ese proceso, los editores de Planeta formaron parte de una intervención concreta sobre los temas de agenda mediante numerosos éxitos editoriales que anticiparon e instalaron un debate de fondo.

Desde el punto de vista editorial, estos libros cubren o anticipan contenidos que pueden convertirse en tendencias de lectura, que son apropiadas por sus lectores y, a su vez, los 
movilizan. En este contexto, los editores forman un eslabón primordial en esa mediación que ocurre entre la producción de un texto y su llegada al público.

Teniendo en cuenta la evolución creciente de estos libros en el período, pueden considerarse tres tipos de "productos logrados", que diferencian a sus editores por la "energía simbólica" invertida en el proceso de producción: a. instantbooks, que refieren a un acontecimiento puntual que ya estaba siendo abordado en los medios y que es convertido en libro en poco tiempo; b. libros "necesarios", según sus editores, los cuales refieren a productos que se insertan en debates políticos más amplios que un acontecimiento puntual, pero que tienen fuerte presencia en los medios. Finalmente, los c. libros que anticipan un humor social, una tendencia conformada a partir de su publicación, lo que convierte a los editores en "descubridores" de temas aun no tratados en los medios. Durante los años del kirchnerismo, estos tres tipos de libros escritos sobre temáticas de coyuntura política fueron acompañados por buenas ventas, según afirman sus editores y los datos disponibles (Saferstein, 2016).

\section{El caso ferroviario en el mercado editorial}

La intensa dinámica que los ferrocarriles de la RMBA tuvieron en su evolución entre los años 2002-2015, operó como nutrido insumo para la elaboración de libros políticos que abrieron un interrogante acerca de las prácticas corruptas efectuadas por funcionarios de Gobierno de las gestiones kirchneristas (2003-2015). En el caso ferroviario, los entramados entre los distintos actores involucrados en la provisión y control del servicio pasaron a estar en el foco de la escena. Principalmente las negativas condiciones de prestación traccionaron la atención social ante la necesidad de identificar causas y responsables de su profundo deterioro. El carácter que asumieron dichas relaciones y su vinculación con la degradación del servicio, fueron progresivamente visibilizadas en la escena pública a partir de una serie de acontecimientos destacados: los ataques de pasajeros a trabajadores, formaciones y estaciones (ocurridos con mayor intensidad entre los años 2005-2008); el asesinato de Mariano Ferreyra, joven militante del Partido Obrero (20 de octubre de 2010) y la ya mencionada Tragedia de Once del 22 de febrero de 2012 (Hernández, 2017).

Los episodios de violencia colectiva protagonizados por los pasajeros tuvieron un intenso seguimiento mediático, no así en el mercado editorial. En esta instancia, comenzaron a instalarse los lineamientos de su problematización en los que la corrupción no emergía por entonces como elemento explicativo. A diferencia, los casos de Mariano Ferreyra y Once provocaron que autores, principalmente periodistas, pero también escritores y hasta una de las familiares de víctimas del accidente, intervinieran en la producción de visiones sobre la política coyuntural que atravesaba a los ferrocarriles a través del segmento de libros trabajado en el 
apartado anterior, complementados con apariciones mediáticas y manifestaciones públicas. Ambos acontecimientos fueron sustrato fértil para el desarrollo de investigaciones periodísticas en las que se conjugaron el avance de las respectivas causas judiciales, con las elaboraciones de periodistas seguidores de la temática así como con el "olfato" editorial que sintetizó estos movimientos y los canalizó en la producción de libros sobre el caso y la construcción y posicionamiento de autores especialistas en la temática.

A partir del año2011 los grandes grupos editoriales, principalmente Planeta, pero también Sudamericana-Random House, publicaron libros que tienen como eje al tema de los trenes argentinos. En febrero salió a la venta ¿Quién mató a Mariano Ferreyra?, de Diego Rojas donde se le da tratamiento a la situación de los trabajadores tercerizados del ferrocarril de la línea Roca. En sus páginas pone de manifiesto la relación entre sindicatos, empresas prestatarias y funcionarios del gobierno del Estado en la producción del servicio, configurando una tríada en pos de la obtención de beneficios particulares a expensas de la precarización laboral. Al mismo tiempo, el libro rescata la trayectoria vital de Mariano Ferreyra como militante político.

En septiembre de ese mismo año Planeta publicó El rekaudador. Ricardo Jaime: la cara de la corrupción en la era kirchnerista, de Omar Lavieri (reeditado en junio de 2016). Una biografía no autorizada de Ricardo Jaime, el Secretario de Transporte entre 2003 y 2009, condenado por casos de corrupción. Lavieri se ocupa de desentrañar un supuesto armado político con base en la administración fraudulenta de los recursos del Estado a través de la figura del Secretario de Transporte y a partir del cual se referencia a un esquema de corrupción que trasciende hacia el sistema político en general.

En julio de 2012, cuatro meses después del accidente, Planeta publicó Once. Viajar y morir como animales, de Graciela Mochkofsky, una crónica de los sucesos inmediatamente posteriores al choque de Once. Allí se contextualiza el accidente, teniendo en cuenta las condiciones de prestación del servicio y las vivencias de las víctimas y de una diversidad de actores intervinientes en la resolución de la emergencia.

Sudamericana también abordó la temática en mayo de 2015, cuando publicó Los platos rotos: Memoria y balance del Estado kirchnerista, escrito por los periodistas Diego Cabot y Francisco Olivera. El libro avanzó en caracterizar al Estado argentino como "obsoleto, incapaz, ineficiente y corrupto", a partir de una mirada puesta en los distintos servicios públicos. En este caso, los ferrocarriles son abordados en el marco de un entramado más amplio como escenario donde hacer observables rasgos asociados a las prácticas de los gobiernos y al avance del Estado en la gestión de sectores estratégicos.

Finalmente, en febrero de ese año Planeta lanzó Desde mis zapatos, de María Luján Rey, madre de una de las víctimas del accidente de Once. El caso de Lucas Menghini Rey, hijo de la autora, cobró una visibilidad particular por la demora de sesenta horas por parte de los 
servicios de emergencia en encontrar sus restos mortales. El libro rescata bajo el formato de diario personal lo vivido en la búsqueda, el duelo y las implicancias políticas que el accidente tuvo en su vida al posicionarse como una de las referentes del movimiento de familiares de Once. El movimiento se posicionó en el espacio público con una potente llegada de su lectura respecto de la cuestión ferroviaria. En sus recurrentes actos y documentos se aludió a un entramado de relaciones entre empresarios, organismos de control y funcionarios del gobierno del Estado en la producción de un servicio deficiente a expensas de las condiciones de viaje y seguridad de los pasajeros (Hernández, 2017).

Portadas de los libros publicados por Planeta y PRH sobre la cuestión ferroviaria

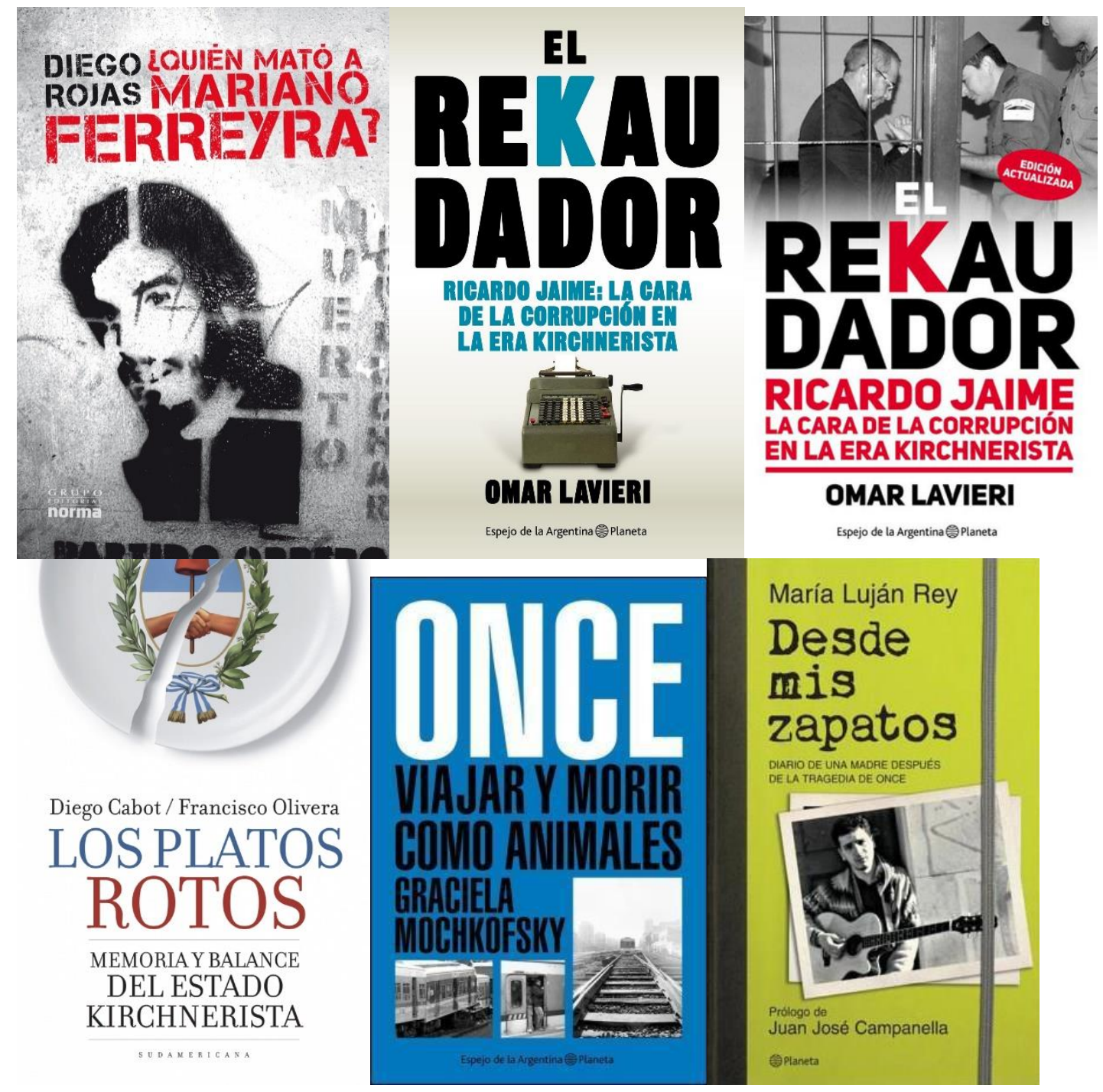

Fuente: World wide web 
Estos libros comparten aspectos en el orden de su temática y discurso y de su modalidad de producción editorial. Desde su discurso, toman la cuestión de la corrupción en el sistema ferroviario como eje transversal. En cuanto a su modalidad productiva, son libros construidos en un lapso breve de tiempo, como reacción editorial a acontecimientos coyunturales con tratamiento mediático amplio. Esto los ubica en la categoría de "instantbooks", libros instantáneos y fugaces que buscan un impacto masivo. Se trata de productos cuyas ideas surgen desde los mismos editores, quienes identifican una temática presente en la agenda que puede generar impacto. En este sentido, estos libros apuntan a cubrir un hecho puntual noticia, acontecimiento, proceso- que el editor selecciona entre una masa de información disponible y presente en poco tiempo.

Los instantbook son publicados por las grandes editoriales porque estas empresas son las que cuentan con una estructura que les brinda una capacidad de maniobra y de error, que las más pequeñas no pueden afrontar. Según el Director de Planeta, este tipo de libros enfrenta el riesgo de que "... por un lado, el tema se agote en los diarios y, por otro, que se termine cuando todavía está largando el libro" (Picabea, 2008). Es decir, que funcionan según los criterios más comerciales, que en este caso se homologan a los del campo periodístico: una noticia que tiene la característica de ser un bien "perecedero" (Bourdieu, 1995) es tomada por una editorial que compite con las de su tipo por obtener la primicia de los medios y editarla como libro desde una lógica comercial.

Los libros de Rojas, Mochkofsky y Rey están anclados a acontecimientos puntuales en el sistema ferroviario. Son el resultado de la "ingeniería editorial" puesta a punto para transformar de manera veloz y oportuna eventos trágicos en un libro. Es en el análisis de un caso (en el de Rojas, el asesinato de un militante político y en los otros dos, el accidente de Once), el lugar desde donde se trasluce la dinámica de la coyuntura política más general. En particular, el libro de María Luján Rey toma un matiz singular al ser una narrativa autobiográfica desde la que la autora recupera su experiencia personal como madre de una víctima. Esto refuerza la línea argumentativa del libro, pero tensa la categoría de instant, ya que su publicación no está atada a la cercanía temporal del hecho puntual, sino más bien a un aniversario del accidente. Desde el punto de vista editorial, este aniversario opera como momento propicio para visibilizar la narrativa de la autora, cuya cercanía con el caso la atraviesa desde un lugar personal y no exterior, como ocurre con los periodistas. El testimonio de la madre de una víctima ante un aniversario del hecho que produjo esa muerte, funciona como oportunidad editorial y comercial potencial.

Por su parte, los libros de Lavieri y de Cabot y Olivera parten del supuesto de que la política argentina está atravesada por la corrupción, abordándola desde una pluralidad de acontecimientos coyunturales más allá del caso de los ferrocarriles. Estos libros trasladan a un 
libro una serie de acontecimientos, noticias y datos ya presentados en la prensa y en el sistema mediático (como fueron los casos de corrupción política y empresarial) dándole un carácter sistemático. En estos casos, el sistema ferroviario les sirve a los autores como un escenario ejemplar para poner de manifiesto y hacer observable a partir de su caso particular el entramado de relaciones que reflejaría la corrupción, en la línea de lo realizado por la ya citada colección Espejo de la Argentina.

\section{La biografía no autorizada de Ricardo Jaime, de Omar Lavieri}

Omar Lavieri es un periodista de investigación con una trayectoria de treinta años de experiencia en distintos medios de prensa gráfica como Clarín, Perfil e Infobae, televisión como panelista en A24- y radio, como columnista en el programa de Víctor Hugo Morales en Radio Continental. Luego de 25 años de trabajo dedicado a investigar casos de corrupción política y empresarial, El Rekaudador. Ricardo Jaime: la cara de la corrupción en la era kirchnerista fue su primer y, hasta el momento, único libro. El libro, con una tirada inicial de 4.000 ejemplares, salió publicado por Planeta en Espejo de la Argentina, colección insignia en el género de libros sobre coyuntura que toman a la corrupción como argumento principal.

La investigación que derivó en la publicación del libro comenzó, según su autor, en 2008 como un caso más de enriquecimiento ilícito sobre los que acostumbraba a investigar. Siguiendo una denuncia contra Ricardo Jaime radicada en la justicia, el periodista comenzó una investigación cuya primera aparición pública la realizó a través de su propio blog y en el programa de radio en el que trabajaba. Al año siguiente, ya como redactor del diario Clarín, Lavieri firmó allí una nota sobre otro caso de corrupción que vinculaba a Jaime con un empresario ligado al sistema de transporte de pasajeros. En noviembre de ese año, Lavieri publicó en el diario una serie de mails que comprometían al ex Secretario de Transporte, desencadenando una repercusión mediática que derivaría en la aparición de ese tema en trece portadas seguidas de Clarín. Entre los temas que se destacaban en la denuncia mediática y judicial, se encontraban aspectos vinculados a la compra de trenes a España, los subsidios girados a la empresa Trenes de Buenos Aires y los vínculos entre el funcionario y la empresa. La amplia cobertura mediática del caso impulsada por Lavieri desde Clarín se enmarca en el momento de plenitud del conflicto de la corporación mediática con el gobierno a raíz de la sanción de la Ley de Servicios Audiovisuales en 2009 (3).

En este sentido, el contexto de vigencia mediática del caso, que no se reducía a Clarín, sino también a los principales medios articulados en la disputa frente al gobierno kirchnerista, operó como fuente de atracción para la editorial Planeta, que vio en Lavieri al periodista indicado para publicar un libro sobre el caso. Las trayectorias laborales previas de los editores, que en 
muchos casos tuvieron experiencias profesionales como periodistas en redacciones de diarios, televisión y radio, los insertan en redes de contacto que coinciden con las de los escritores que contratan: "Por ser periodista naturalmente me llegan más libros periodísticos por ex colegas, entonces publico muchos libros periodísticos" (Editora 1, RH, Comunicación personal, 5 de agosto, 2013). En el caso que se está analizando, su llegada a la editorial fue a través de un colega periodista que funcionó como nexo con el director de Planeta, quien había iniciado su carrera editorial en el departamento de Prensa.

Cuando yo revelé eso, un amigo, que es amigo de Ignacio Iraola, director de Planeta, me dijo "Che, acá hay un libro", e Iraola dijo "Si"... (...) Eso fue en el verano del 2011 (...) Me llamó Ignacio Iraola, y me dijo “Necesitamos el libro para septiembre, ¿estás?”... y salió en septiembre (Omar Lavieri, Comunicación personal, 2 de junio, 2017).

Atentos a la agenda mediática, los editores reconocen las temáticas coyunturales vigentes y piensan libros en función de su impacto inmediato, mediático y comercial. En esta clase de títulos el editor prioriza la temática que se puede conjugar o no con la trayectoria del autor, ya que la preocupación principal es cumplir con los "tiempos y formas" que exige la editorial. La necesidad de publicar mientras se trata el tema en los medios conduce a que el proceso adquiera un carácter veloz, al punto tal que sea necesario un trabajo fuerte de escritura por parte del autor y del editor, en quien recae la tarea de adaptar la escritura periodística al formato de libro.

Para El rekaudador, Planeta contrató al periodista más especializado en la temática, ya que Lavieri era el principal referente en la cobertura del tema "Jaime" en la prensa. En ese sentido, contaba con el material para que el libro pueda ser publicado en los tiempos exigidos. Su falta de experiencia como autor de libros no impidió su contratación, proveyéndole la editorial herramientas para el trabajo de escritura.

\footnotetext{
Me reuní con Iraola, me dijo “¿Qué tenés?" le dije "Tengo todo esto" y me... me contactó con un editor que me fue guiando. Era todo enorme, tuve que acortar, elegir algunos capítulos. No era lo mismo, tenía buena parte del material escrito en notas, pero tenía que agrandarlo, presentar mejor a los personajes. Conseguí algunas cosas que no había publicado (Omar Lavieri, Comunicación personal, 2 de junio, 2017).
}

Como sucede en los instantbooks, en los que la producción del texto debe ser igual de veloz que el resto del proceso productivo, los libros son coescritos junto al editor o a un ghostwriter, un escritor profesional que no firma pero realiza la escritura de un libro firmado por otro. Así, las ideas y los discursos de una obra se le atribuyen a un único sujeto fabricado que aparece como creador (Agüero, 2008). Con mucha fuerza desde la conformación de conglomerados 
editoriales $\mathrm{y}$, paralelamente, al éxito de los libros políticos en los últimos años, los periodistas de investigación se conformaron como protagonistas visibles del segmento de libros que instalaron, potenciaron y le dieron entidad a la corrupción como problema público (Pereyra, 2013).

En este sentido, Lavieri forma parte del conjunto de periodistas quienes, como complemento de su trabajo, pasaron a tener una participación clave en el mercado editorial, el cual le dio la posibilidad de construirse como "especialista" en la temática de corrupción. A raíz del lanzamiento del libro el periodista fue entrevistado en sucesivas oportunidades (Gaceta, 2011; Lavieri, 2011), pero su difusión mediática cobró mayor peso a medida que avanzaba la causa judicial hasta llegar a la detención del ex funcionario en 2016 (AlconadaMon, 2016; Biassati, 2013; Infobae, 2016a; Wiñazki, 2016). El procesamiento y encarcelamiento de Ricardo Jaime en 2016 fue la oportunidad para que el libro sea reeditado con una nueva portada. A raíz de que algunos elementos del libro hayan sido tomados en consideración en la causa, se potenció su campaña de difusión al ser presentado como "el libro que llevó a Ricardo Jaime a prisión" (Infobae, 2016b).

La importancia del libro político está vinculada a la circulación de los autores y de sus libros a través de distintos espacios desde los que sus discursos cobran mayor visibilidad y efectividad. Además de la campaña de prensa potenciada por el acompañamiento del tema en los medios, es relevante observar cómo el autor pone en valor al fruto de su investigación, puesto que desde sus discursos se pueden observar síntomas del "efecto libro" en la esfera social (Darnton, 1993).

\footnotetext{
Con Jaime preso el libro adquiere una entidad diferente (...) El asunto se reavivó [también] con la tragedia de Once (...) Había mucha gente que se referenciaba en el libro para explicar cómo había sido el negocio porque, además en libro me ocupo de dos empresarios corruptos especialmente, que son Otero y Cirigliano (...)Jaime fue condenado por esto que yo te conté (Omar Lavieri, Comunicación personal, 2 de junio, 2017).
}

Desde el medio editorial, los periodistas satisfacen las expectativas de la escritura rápida de libros que potencia su visibilidad gracias a la intervención de sus autores en otros espacios mediáticos desde donde promocionan sus propios libros y los de sus colegas. Además, la publicación de un libro en el tiempo en que el tema se encuentra en vigencia, le aporta a la editorial un reconocimiento y una capacidad de insertarse en la discusión pública. Para los periodistas, la escritura y publicación de un libro aparece como una oportunidad para profundizar ciertas líneas de investigación de manera más amplia y dar a conocer sus propias ideas y posicionamientos, pero sobre todo para construirse como autor de libros, bien cultural con alta valoración social. 
El libro, lo que te da, es la posibilidad de hacer algo diferente a lo que hacés en la diaria (...) Me puso contento, no me olvido más la sensación que tuve cuando en la radio me llegaron los primeros dos ejemplares, en un sobre... Estábamos al aire y agarré el sobre con los libros, lo rompí, hice un ruido bárbaro, Fernando Bravo se puso mal porque lo interrumpí... hice un ruido bárbaro... estaba muy contento, es algo importante (Omar Lavieri, Comunicación personal, 2 de junio, 2017).

Además del reconocimiento específico que le da a la editorial y al autor la publicación de un instantbook, las características mencionadas en torno a la valoración social del libro -más allá de que, en estos casos, sean productos con un evidente sentido comercial- le aportan fuerza a una temática que circula por la escena pública y mediática.

\begin{abstract}
El libro le dio al tema una entidad distinta [al tratamiento en la prensa]. Porque no te olvides que esto, en el año 2010 con el gobierno en guerra con Clarín, mucha gente decía "Esto forma parte de...". No se daban cuenta de lo que había pasado, no se dieron cuenta de lo que significaba (Omar Lavieri, Comunicación personal, 2 de junio, 2017).
\end{abstract}

Más allá del caso puntual en el cual el tratamiento mediático del tema se contextualiza en la disputa entre el gobierno y Clarín, el sistema editorial es central en que el autor se conforme como referente y el libro se construya como obra que funciona jurídica pero sobre todo socialmente, como "prueba" para comprobar, en este caso, un entramado particular de corrupción.

Yo bauticé a la tragedia de Once como un caso de corrupción seguida de muerte, lo dije en la radio el primer día, 22 de febrero del 2012, porque, obviamente, yo había escrito un libro donde decía esto. Y no tengo dudas de que quedó claro, en éste caso quedó claro y otros tantos, digo, Cromañón, Iron Mountain. Hay un montón de casos donde queda claro que la corrupción mata, (...) En éste caso está probado, y creo que buena parte de lo que ayudó a probarlo se escribió antes, lo escribí yo y mucha gente, yo hice el libro (Omar Lavieri, Comunicación personal, 2 de junio, 2017).

En ese sentido, El rekaudador aparece no sólo como un instantbook que opera como bien comercial para la editorial al ser comprado y leído por un amplio público lector de libros políticos, sino como también como obra autónoma, atribuida a un autor y a una editorial, que cobra relevancia social en cuanto a la visibilidad y circulación de un tema y de un referente en la escena pública. 


\section{Viajar y morir: la crónica de la tragedia por Graciela Mochkofsky}

En un contexto donde los ferrocarriles metropolitanos venían siendo escenario de accidentes de envergadura con fuerte repercusión mediática, el caso de Once se convirtió en corolario de los acontecimientos que operaron en la instalación de la cuestión ferroviaria en la escena pública. Como sucedió con el caso Jaime retratado en el libro de Lavieri, en consonancia con la prensa y el ámbito de la justicia, las grandes editoriales como Planeta abordaron el accidente de manera veloz y efectiva.

Once: viajar y morir como animales de Graciela Mochkofsky se publicó en julio de 2012, con una tirada de seis mil ejemplares, también como parte de la colección Espejo de la Argentina. Planeta publicó este libro a 4 meses y 8 días de sucedido el accidente del 22 de febrero del mismo año, lo que muestra la rápida reacción editorial ante un suceso disruptivo que se vuelve oportunidad. Teniendo en cuenta que el trabajo con los medios masivos de comunicación, televisión, radio, prensa y redes sociales, permitió a los editores operar como productores de contenidos basados en tendencias más o menos visibles, el trágico accidente de Once fue leído por los editores de Planeta como una oportunidad para la incorporación de un nuevo libro a su plan editorial anual. Necesariamente, publicar un nuevo libro inmediatamente después de que suceda un hecho de estas magnitudes repercute en el circuito de la editorial. Como afirman los miembros del grupo,

\footnotetext{
Hay que correr en ese mes y medio que hay que sacarlo. Tenés que tener una red de distribución en todo el país con un nivel de logística relativamente rápido. Planeta lo tiene; hay editoriales que lo pueden hacer y otras que no" (Gerente de Marketing, Planeta, Comunicación personal, 24 de enero, 2013).
}

Si te llega un libro espontáneo que no tiene que ver con el plan y pensás que vas a vender, lo hacés. En Planeta no se le hace asco a nada (Director Editorial 2, Planeta, Comunicación personal, 23 de julio, 2013)

La creación de instantbooks requiere de grandes inversiones, no sólo para la campaña de difusión que se realiza, sino también porque la editorial contrata a un escritor que debe elaborar el manuscrito a contrarreloj. Cuando sucedió el accidente, Graciela Mochkofsky se encontraba trabajando en un libro para la editorial en la que ya había publicado anteriormente. Esto cambió el curso de su trabajo. Hubo una decisión editorial y autoral de dejar de lado el proyecto que se venía realizando, para pasar a ocuparse de la elaboración de un libro sobre el caso de Once. Como cuenta una Jefa de Prensa: "En Plantea sacar un instantbook es realizable (...) paran las rotativas y meten ese libro" (Jefa de prensa, RH, Comunicación personal, 11 de junio, 2013). 
Sin embargo, la actitud reactiva de la editorial se conjugó con la oportunidad de que Graciela Mochkofsky acepte la escritura del libro sobre Once en poco tiempo. La periodista tiene una amplia trayectoria tanto en el ámbito de la prensa como en el mercado editorial, así como en el ámbito de formación en la disciplina periodística en la Universidad Torcuato Di Tella. Integró las redacciones de Página/12 y La Nación, fue columnista de Perfil, de El País (España). Fue colaboradora de las revistas The Paris Review, The New Yorker, Letras Libres, Etiqueta Negra, Gatopardo, SOHO y TheClinicy directora de la revista digital El puercoespín. Publicó cinco libros antes de Once: Caso Cóppola, una crónica del fin del menemismo (Sudamericana, 1997), en coautoría con Gabriel Pasquini; Timerman, el periodista que quiso ser parte del poder (1923-1999) (Sudamericana, 2003), nominado al Premio Lettre Ulysses de Reportaje Literario en Berlín en 2004; Tío Boris, un héroe olvidado de la Guerra Civil Española (Sudamericana, 2006); La Revelación, una historia real (Planeta, 2007) y Pecado Original. Clarín, los Kirchner y la lucha por el poder" (Planeta 2011). Como corolario de esta trayectoria, dirige desde 2015 la maestría de periodismo en español de la prestigiosa universidad City University of New York (CUNY). Su derrotero la ubica en una posición de referencia dentro del campo periodístico.

La publicación de libros de coyuntura escritos de manera rápida por autores reconocidos por las instancias prestigiadas del campo en el que participan, opera como un plus que le da mayor legitimidad al libro en cuestión. Para sus editores, éstos funcionan a partir de una lógica que media entre la búsqueda de rendimiento comercial y la visibilidad y reconocimiento de sus autores. Los editores demuestran interés en periodistas que manifiestan una defensa de los valores legítimos del "oficio" desde una lógica que en parte deniega lo económico. Aun en un espacio atravesado fuertemente por el peso de lo comercial, en el cual los medios operan desde una lógica mercantil para llegar a una amplia cantidad de lectores, los periodistas disputan por obtener reconocimiento frente al público y frente a sus pares (Baldoni, 2010). Tal reconocimiento está mediado por la misma lógica del mercado, pero tensiona con operaciones de búsqueda de prestigio. En este sentido, a diferencia de las posiciones más visibles y masivas $-\mathrm{y}$, por ende, más comerciales-, existen libros políticos publicados incluso por las grandes editoriales, pero escritos por periodistas cuya manifiesta vocación de intervención pública y de valoración del oficio periodístico les concede un lugar legítimo, el cual excede su pretensión comercial.

Este posicionamiento se observa en el discurso de la autora, sumado a la sensibilidad del caso del accidente que operó como movilizador y motivador para la escritura. La tragedia ferroviaria la interpeló personalmente para avanzar en la investigación, al mismo tiempo que contribuyó a crear un sustrato fértil para la editorial, al conformar públicos potencialmente consumidores de los libros movilizados en torno a la cuestión. La conjunción de estos elementos contribuyó a la elaboración de un producto editorial comercial y simbólicamente efectivo para la editorial, para la autora y para su mercado. 
El accidente fue el 22 de febrero. Yo hice el libro exactamente en tres meses. En realidad cuando ocurrió el choque, yo estaba trabajando... yo en realidad voy por mi sexto libro y en general me tomo bastante tiempo. Hasta seis años me he tomado para un libro y estaba trabajando en un libro también de largo aliento cuando ocurrió, me conmovió tanto y me pareció que había ahí una historia importante para contar (Rojas, 2012).

Desde la visión de la autora, que el libro pudiera elaborarse y publicarse cercano a los acontecimientos, permitía obtener un producto con el potencial para aportar a la dinámica publica en torno a un tema con plena vigencia: "me parecía interesante también que apareciera el libro y escribir esta historia para el momento en que sigue siendo un tema de debate público. Para aportar alguna información que sirviera para ese debate" (Rojas, 2012). En ese sentido se delinearon una serie de notas, reseñas y entrevistas a la autora en consonancia con la publicación del libro (Gorodischer, 2013; La Nación, 2012; Radio Continental, 2012; Rojas, 2012).

El libro se ocupa de reconstruir el accidente de Once a partir de la historia de diez de los afectados en el choque, condensadas en la sección titulada "Crímenes". En la segunda parte, "Culpas" y "Castigos", busca dar cuenta de los elementos explicativos que posibilitaron el accidente, por qué ocurrió y cuáles fueron las responsabilidades involucradas. Más allá de contribuir a identificar el encadenamiento de factores que actuaron como precipitantes del accidente, el libro se preocupa por aportar a la dilucidación de los elementos estructurales que llevaron a que el sistema ferroviario se convirtiera en escenario de un accidente de envergadura: "la segunda parte de la investigación es la historia más político-ideológica empresarial que explica las razones que llevaron a esto" (Rojas, 2012).

La corrupción aparece como variable explicativa de la degradación ferroviaria y la producción del accidente de Once, aunque no puede entenderse esta categoría sin identificar a los elementos que la configuran. Para la autora la eficacia explicativa de la frase "la corrupción mata", reside en la capacidad de desentrañar los elementos que la configuran para que efectivamente pueda operar como una categoría que sintetiza un entramado particular de relaciones entre actores.

\footnotetext{
Hay una idea de bueno, "esto es por la corrupción, la corrupción mata". Bueno, sí. La corrupción mata. Entonces yo tengo la investigación sobre la corrupción y cómo se ha robado, las sospechas que hay de cómo se ha robado el dinero de los subsidios en estos diez años. Esto es posible por un cinismo empresarial y político (Rojas, 2012).
} 
La clave de lectura que la autora espera obtener de parte de quienes reciban su libro es la de instalar una denuncia, una prueba, que, además de intervenir en el sistema político y judicial, también pueda interpelar a sus lectores desde una dimensión emocional.

Lo que a mí más me importa es que libro sea leído, es una denuncia con lo cual quiero que conmueva e indigne (...) Es ambicioso pero me gustaría que la gente que viaje en el Sarmiento o pasa por cosas así sienta que su vida está contada en esta historia (Rojas, 2012).

A diferencia del caso de Lavieri, en donde la adopción de un tono pretendidamente "objetivo" presenta al libro como una investigación neutral, en tanto prueba periodística o incluso judicial, en este caso la autora aporta desde la crónica su involucramiento personal sin dejar de lado el "dato" y la denuncia, presentados de un modo cercano al lector. En este sentido, el libro es considerado como un proyecto que tuvo como objetivo visibilizar una temática y promover la discusión, desde un plano autónomo e independiente. Estas cuestiones fueron consideradas por sus editores, quienes motorizaron el proyecto por la temática del libro, pero también como parte de una operación que posiciona a la editorial en tanto publica a una autora prestigiosa en el periodismo y el mercado editorial, en tanto firma autorizada y legitimada más allá de los resultados comerciales.

Teniendo en cuenta estos dos casos, se puede observar cómo el sistema editorial logra articular una temática presente en la arena mediática con un texto de autores con mayor o menor grado de reconocimiento dentro del campo en el que intervienen, para así sentar un posicionamiento público sobre una determinada cuestión. Para el caso del sistema ferroviario, las editoriales retomaron y reforzaron la visión bajo la cual este se convirtió en un problema.

\footnotetext{
A mí me gusta desenmascarar a un tipo que está haciendo el mal. Y los políticos afanan. Quedó claro nunca tanto como lo que fue el choque del tren en Once, que la corrupción realmente mata, loco. Y estos hijos de puta afanan. Yo crecí con un desprecio profundo al político, entonces a mí me gusta buscarle la mierda y cuando la encontrás y lo publicás, realmente está bueno (...) Estoy buscando los flancos corruptos o feos que a mí no me gustan del macrismo para plantear un libro, como lo hice con el kirchnerismo (Director Editorial 4, Planeta, Comunicación personal, 14 de junio, 2016).
}

En la postura del director editorial de Planeta pueden leerse, por un lado, la intención particular del editor y su "sensibilidad" para intervenir, a través de su catálogo, sobre una problemática puntual, en este caso, las consecuencias mortales de la corrupción. Por otro lado, esta vocación de intervención confluye con la "ingeniería editorial" que provee una corporación como lo es Planeta, con poder de llegada a las librerías de todo el país, de lograr reseñas, notas y visibilidad mediática, así como de elaborar campañas publicitarias y de marketing. Esta 
articulación se potencia al tener en cuenta la colección en la que los casos mencionados se publican, la cual tiene una impronta histórica característica, que es reproducida más allá de las coyunturas puntuales. De este modo, el posicionamiento del director editorial citado se evidencia en estos libros y en esta colección, pero está apegado y coincide con la orientación comercial que tiene Espejo de la Argentina y Planeta desde su surgimiento.

\section{Conclusiones}

Los debates políticos que atravesaron al gran público durante los últimos años, fueron motorizados por el periodismo y otros espacios culturales entre los que se destaca el sector editorial, espacio que se hizo eco de las discusiones y las plasmó en libros exitosos. Los editores materializaron en libros concretos las discusiones y debates políticos que atravesaron al período de los gobiernos kirchneristas. Estos actores participaron en el sistema de consumos culturales, al canalizar exitosamente los posicionamientos políticos de los lectores mediante segmentos de libros de coyuntura. Captaron temáticas y acontecimientos con potencialidad de repercusión mediática, entre ellos, la cuestión del sistema ferroviario, que ancló de manera efectiva en sectores del público.

La visión que proponen los libros mencionados, así como las prácticas de los editores en torno a su producción, refuerza la idea de que la corrupción ha sido instalada como tema desde los años noventa, a partir de la intervención de un entramado de actores entre los que se destacan las industrias culturales como la editorial y el sistema mediático. Con estos casos, se puede ver que el espacio editorial tomó la cuestión de los ferrocarriles como una oportunidad potencial no solo para cumplir con el imperativo de "vender libros", sino que también contribuyó a desarrollar, reproducir y consolidar la idea extendida acerca de la corrupción como tema que atraviesa la política y la vida pública. Los modos de producción y difusión editorial, la relación entre editores y autores, la difusión de los libros y la construcción de la figura de autor revelan un potencial para la intervención pública desde el espacio editorial que debe ser tenido en consideración.

La cultura opera activamente sobre el mundo de los problemas públicos y el mercado editorial es un actor relevante, al publicar libros que pueden haber sido tomados en cuenta como fuentes para causas judiciales resonantes, valorados como documentos históricos o como medio para presentar social y públicamente una temática. Junto a la prensa y a otros espacios de producción, conforma un sistema de comunicación que instalan temáticas y posicionan a sus portavoces. En el caso que se analizó, colaboró con la visión presentada por la prensa y por el movimiento de familiares de víctimas de Once en torno a las consecuencias negativas de la corrupción, en tanto que esta puede llegar a "matar". 
La "corrupción mata" tuvo eficacia política al instalar a la cuestión ferroviaria y al motorizar e interpelar al sistema jurídico y gubernamental. Desde sus respectivas competencias, estos sistemas respondieron avanzando, por un lado, en la resolución de la causa judicial y por otro al motorizar la respuesta estatal bajo la forma de políticas públicas destinadas a jerarquizar y modernizar al servicio de transporte ferroviario de pasajeros. Esta efectividad fue reforzada por el mundo editorial, donde los libros que adscribieron a esta visión tuvieron una amplia llegada y repercusión. Las condiciones de posibilidad de los grandes grupos editoriales de producir sincronizadamente con los ritmos de coyuntura a la par de un olfato editorial entrenado para reconocer los temas resonantes y a los autores apropiados para ser publicados, dan cuenta de una potencia. Un futuro análisis acerca de los modos de lectura de estos libros en tanto práctica cultural significativa permitirá profundizar acerca de los efectos que produce el sistema editorial -y el amplio sistema de comunicación que lo incluye- en torno a la construcción del servicio ferroviario como problema público.

\section{Agradecimientos}

Agradecemos especialmente a Alejandro Dujovne por sus comentarios a una versión preliminar de este trabajo.

\section{Notas}

(1) El 22 de febrero de 2012 a las 8.33 a.m. una formación del ferrocarril Sarmiento chocó contra la barrera de contención del andén dos en la estación terminal de Once. El accidente dejó un saldo de 52 fallecidos (uno de ellos por nacer) y 789 heridos.

(2) Estos libros se encuentran clasificados bajo cuatro materias no excluyentes: "Ensayo argentino", "Ensayo político", "Ensayo político argentino" e "Investigación periodística". Teniendo en cuenta esta información obtenida de la Agencia Nacional de ISBN, se construyó una base de datos con los registros encasillados bajo estas materias y géneros.

(3) La Ley de Servicios de Comunicación Audiovisual reemplazó a la Ley de Radiodifusión de 1980. Teniendo en cuenta que el espíritu de la ley apuntaba a "desmonopolizar" el arco mediático, su promulgación generó tensiones y disputas entre el gobierno y las empresas periodísticas. Esta tensión se tradujo en la construcción de un clivaje entre el llamado "periodismo independiente" y el llamado "periodismo militante". Para mayor profundidad sobre el tema se recomienda la lectura del trabajo de Baldoni (2012).

\section{Bibliografía}

Baldoni, M. (2010). Las transformaciones de los medios de comunicación y el periodismo 
político durante la década del ochenta y del noventa en Argentina: un recorrido por las trayectorias profesionales de Jorge Lanata y Luis Majul. En VI Jornadas de Sociología de la UNLP. La Plata, UNLP.

Baldoni, M. (2012). La disputa entre periodismo independiente y periodismo militante: apuntes para analizar las tensiones en la ética periodística en la Argentina contemporánea. Quórum Académico, 9(2). Recuperado de http://www.produccioncientificaluz.org/index.php/quorum/article/view/17597

Bourdieu, P. (1995). La influencia del periodismo. Causas y azares, 3, pp. 55-64.

Bourdieu, P. (2009). Una revolución conservadora en la edición. En Intelectuales, política y poder (pp. 223-270). Buenos Aires: Eudeba.

Darnton, R. (1993). La France, ton café fout le camp!: De I'histoire du livre à I'histoire de la communication. Actes de la recherche en sciences sociales, 100(1), pp. 16-26. Recuperado de https://doi.org/10.3406/arss.1993.3068

Dujovne, A. (mayo de 2016). Frankfurt, hablame de mí. Revista Anfibia. Recuperado de //www.revistaanfibia.com/ensayo/frankfurt-hablame-de-mi/

Gusfield, J. R. (2014). La cultura de los problemas públicos. El mito del conductor alcoholizado versus la sociedad inocente. Buenos Aires: Siglo Veintiuno.

Hernández, C. (2017). Entre conflictos y accidentes. La construcción de los ferrocarriles metropolitanos como problema público. 2002-2015. (Tesis de Maestría). Facultad de Ciencias Sociales, Universidad de Buenos Aires.

Loseke, D. R. (2011). Thinking about social problems. An introduction to constructionist perspectives. New York: Aldine de Gruyter.

Miguel, P. y Saferstein, E. 2016. Ser una esponja de tendencias: los editores y la "intuición de la demanda" en las grandes editoriales. Astrolabio 16: 61-92.

Pereyra, S. (2013). Política y transparencia: la corrupción como problema público. Buenos Aires: Siglo Veintiuno Editores.

Rey, M. L. (2015). Desde mis zapatos: diario de una madre después de la tragedia de Once. C.A.B.A: Planeta.

Saferstein, E. (2016). La década publicada. Los best sellers políticos y sus editores: producción de libros, difusión de temas e intervención pública en el mercado editorial argentino (2003-2015) (Tesis de Doctorado). Facultad de Ciencias Sociales, Universidad de Buenos Aires.

Sorá, G. (2008). Edición y política. Guerra fría en la cultura latinoamericana de los años '60. Revista del Museo de Antropología, 1(1), pp. 97-114.

Thompson, J. B. (2012). Merchants of culture. The publishing business in the twenty first century. New York: Plume. 
Tuchman, G. (julio de 1973). Making news by doing work: routinizing the unexpected. American Journal of Sociology, 79(1).

Valcarce, F. M. L. (2005). El trabajo periodístico y los modos de producción de la noticia: el tratamiento de la inseguridad en la prensa argentina. Question, 1(7). Recuperado de http://perio.unlp.edu.ar/ojs/index.php/question/article/view/108

Vommaro, G., y Baldoni, M. (2012). Bernardo y Mariano: las transformaciones del periodismo político en Argentina de los años ochenta a los años noventa. Medialogos, pp. 59-81.

\section{Notas periodísticas}

Alconada Mon, H. (21 de junio de 2016). Omar Lavieri: Jaime recaudaba para sí mismo y para Néstor Kirchner. Conversaciones en La Nación. Recuperado de http://www.lanacion.com.ar/1911105-omar-lavieri-jaime-recaudaba-para-si-mismo-ypara-nestor-kirchner

Biassati, S. (16 de julio de 2013). Jaime procesado. Entrevista a Omar Lavieri. Otro Tema Todo Noticias. Recuperado a partir de http://tn.com.ar/programas/otro-tema/jaimeprocesado-16072013_399691

Blanc, N. (2013). Los libros de un país dividido. ADN. Recuperado de http://www.lanacion.com.ar/1625613-los-libros-de-un-pais-dividido

Gaceta. (28 de septiembre de 2011). El rekaudador, una investigación sobre el ex secretario Ricardo Jaime. Gaceta Mercantil. Gaceta Mercantil. Recuperado de http://www.gacetamercantil.com/notas/8895/

Gorodischer, J. (29 de enero de 2013). Un relato de la agonía. Clarín.

Infobae (2016a, abril 2). 13 fragmentos de El ReKaudador, el libro que reveló los negocios de Ricardo Jaime. Infobae. Recuperado de http://www.infobae.com/2016/04/02/180143213-fragmentos-el-rekaudador-el-libro-que-revelo-los-negocios-ricardo-jaime/

Infobae. (2016b, junio 11). El Rekaudador, el libro que llevó a Ricardo Jaime a prisión. Infobae. Recuperado de http://www.infobae.com/politica/2016/06/12/el-rekaudador-el-libro-quellevo-a-ricardo-jaime-a-prision/

La Nación (1 de julio de 2012). Viajar y morir como animales. La Nación.

Lavieri, O. (4 de octubre2011, octubre 4). Jaime: las huellas de la corrupción. La Nación. Recuperado a partir de http://www.lanacion.com.ar/1411675-ricardo-jaime-elrekaudador

Página/12 (7 de julio de 2017). PenguimRandom House formalizó la compra de Ediciones B. Página 12. Recuperado de https://www.pagina12.com.ar/48530-la-era-de-laseditoriales-mamushka 
Picabea, M. L. (21 de diciembre de 2008). Las editoriales se reacomodan ante la crisis con el «instantbook». Recuperado de http://edant.clarin.com/diario/2008/12/21/sociedad/s01826488.htm

O' Donnell, M. (9 de julio de 2012). "El tren tiene una carga simbólica muy importante para hablar de la Argentina", dijo Graciela Mochkofsky. Radio Continental, Buenos Aires. Recuperado de: http://www.continental.com.ar/noticias/sociedad/el-tren-tiene-unacarga-simbolica-muy-importante-para-hablar-de-la-argentina-dijo-gracielamochkofsky/20120709/nota/1719470.aspx

Rojas, D. (2012). Entrevista a Graciela Mochkofsky. Plaza de mayo. Recuperado de http://www.plazademayo.com/2012/07/graciela-mochkofsky/

Wiñazki, N. (2016, abril 3). Jaime, símbolo y pionero de dos cualidades del kirchnerismo. Clarín. Recuperado de https://www.clarin.com/politica/Jaime-simbolo-pionerocualidades-kirchnerismo_0_V1zxBBFRI.html 